\title{
Outpatients with irritable bowel syndrome: a comparison of first time and chronic attenders
}

\author{
E A Guthrie, F H Creed, P J Whorwell, B Tomenson
}

\begin{abstract}
Fifty two chronic clinic attenders with irritable bowel syndrome were compared with 97 newly referred patients in respect of physical symptoms and psychiatric status. Profound differences between the two groups emerged. Many abdominal and non-colonic symptoms were perceived as much more severe in chronic attenders compared with first time attenders ( $p<0.0001$ for abdominal pain and abdominal distension). Chronic attenders were much more likely to complain of constant symptoms $(p<0.05)$, and the social consequences of their illness were much more striking $(p<0.0001)$. There was, however, no difference in the prevalence of psychiatric morbidity in the two groups. Clinical trials and other investigations of the irritable bowel syndrome are usually conducted on hospital outpatient populations. The results of this study indicate that the patient populations used for these purposes need to be carefully defined.
\end{abstract}

The irritable bowel syndrome is a common condition affecting approximately $13 \%$ of the general population, ${ }^{1}$ and it accounts for a substantial proportion of patients seen by consultant gastroenterologists in the UK. ${ }^{23} \mathrm{~A}$ great deal of research has been carried out on the condition, and the recent adoption of more strict diagnostic criteria has made comparison between studies more useful. ${ }^{4}$ Research, at present, is focused on three main areas; gut physiology, ${ }^{5}$ psychological factors, ${ }^{6}$ and the evaluation of treatment intervention (both pharmacological and psychological). ${ }^{78}$

There are, however, still problems with the comparison and evaluation of current research approaches. The work of Thompson' suggests that there may be differing subgroups of irritable bowel syndrome patients, which can be categorised according to bowel habit. It remains to be determined whether patients with different symptom constellations have differing patterns of motility or psychological profiles, or respond in a different way to particular treatments. There is some evidence that patients with painless diarrhoea may well comprise a separate group, ${ }^{10}$ but unless researchers clearly delineate the kinds of patients they are studying, findings will continue to be confusing and imprecise.

Using bowel habit alone, however, to distinguish irritable bowel syndrome subjects may not be the best method of categorisation. Recent work by Harvey et $a l^{11}$ suggests that most of these patients respond to simple treatments and reassurance, coupled with a clear explanation of the aetiology of their symptoms. A small group of patients (32\%), however, continues with chronic symptoms that are unresponsive to conventional treatments. Research to date has consistently failed to take account of possible differences in patients who are new attenders at a clinic compared with those who are chronic attenders. This is particularly the case with pharmacological treatment trials, where the importance of the selection of subjects is often ignored. ${ }^{12}$

The aim of this study was to ascertain whether there was any difference between these two groups, in terms of the severity and nature of their symptoms. If there are differences, then clearly this has implications for both future and published research.

\section{Patients and methods}

Fifty two consecutive female patients with symptoms of chronic irritable bowel syndrome, who had been attending a gastroenterological clinic for at least six months without improvement, were compared with 97 consecutive female patients with irritable bowel syndrome who were attending the same clinic for the first time. It is our policy to see tertiary referrals and very chronic patients, such as hypnosis failures, in a special clinic. This study was performed in the general gastroenterology clinic and is therefore representative of the clinic load of other gastroenterologists.

The inclusion criteria for patients with irritable bowel syndrome were abdominal pain, abdominal distension, and an abnormal bowel habit in association with normal haematology, serum biochemistry, rectal biopsy and colonoscopy, or contrast radiology. Patients with painless diarrhoea were excluded.

An extensive assessment of the nature, course, and pattern of bowel symptoms was carried out, including an evaluation of the limiting effect bowel complaints had on each patient's life. The assessment involved a semistructured interview that was conducted in private by the same doctor (EG). Patients were also asked to complete self report questionnaires regarding the severity of abdominal symptoms and the presence of noncolonic symptoms. ${ }^{131+}$ Each symptom was rated on a five point scale - nil, mild, moderate, severe, and very severe. In addition, the severity of each patient's abdominal symptoms was rated by a consultant gastroenterologist (PJW). The 'Psychiatric Assessment Schedule' (PAS) ${ }^{15}$ was used to assess psychiatric status. This semistructured questionnaire is a modified version of the 'Present State Examination'16 that can be used with populations that have neurotic, not psychotic illness. The results were processed by the computer programme CATEGO, to produce 
TABLE I Severity of abdominal symptoms in first time (lst) $\mathrm{v}$ chronic attenders (Chr)

\begin{tabular}{|c|c|c|c|c|c|c|c|c|c|c|c|c|}
\hline & \multicolumn{12}{|c|}{ Severity of symptoms (\%) } \\
\hline & \multicolumn{2}{|l|}{$\mathrm{Nil}$} & \multicolumn{2}{|l|}{ Mild } & \multicolumn{2}{|c|}{ Moderate } & \multicolumn{2}{|c|}{ Severe } & \multicolumn{2}{|c|}{ Very severe } & \multicolumn{2}{|l|}{$d f=4$} \\
\hline & $1 s t$ & $C h r$ & lst & $C h r$ & $1 s t$ & $C h r$ & lst & $C h r$ & $1 s t$ & $C h r$ & $\chi^{2}$ & $\mathrm{p}$ \\
\hline Abdominal pain & 0 & 0 & $26 \cdot 8$ & $3 \cdot 8$ & $62 \cdot 9$ & $34 \cdot 6$ & $10 \cdot 3$ & $44 \cdot 2$ & 0 & $17 \cdot 3$ & $48 \cdot 9$ & $\mathrm{p}<0.0001$ \\
\hline Abdominal distension & 0 & 0 & $54 \cdot 6$ & $5 \cdot 8$ & $39 \cdot 2$ & $30 \cdot 8$ & $2 \cdot 1$ & $32 \cdot 7$ & 0 & $30 \cdot 8$ & $79 \cdot 9$ & $\mathrm{p}<0.0001$ \\
\hline Constipation & $37 \cdot 1$ & $21 \cdot 2$ & $49 \cdot 5$ & 26.9 & $12 \cdot 4$ & $25 \cdot 0$ & 1 & $21 \cdot 2$ & 0 & $5 \cdot 8$ & $32 \cdot 7$ & $\mathrm{p}<0.001$ \\
\hline Diarrhoea & $75 \cdot 3$ & $66 \cdot 7$ & $7 \cdot 2$ & $11 \cdot 8$ & $17 \cdot 5$ & $11 \cdot 8$ & 0 & $9 \cdot 8$ & & & $11 \cdot 4$ & $\mathrm{p}<0.01$ \\
\hline Rectal dissatisfaction & $47 \cdot 4$ & $19 \cdot 6$ & $26 \cdot 8$ & 3.9 & $25 \cdot 3$ & $39 \cdot 2$ & 0 & $25 \cdot 5$ & 0 & $11 \cdot 8$ & $54 \cdot 2$ & $\mathrm{p}<0.0001$ \\
\hline Flatus & $75 \cdot 3$ & $67 \cdot 3$ & $8 \cdot 2$ & $9 \cdot 6$ & $16 \cdot 5$ & $15 \cdot \overline{4}$ & 0 & $5 \cdot 8$ & 0 & 1.9 & 7.9 & $\mathrm{p}=0.09$ \\
\hline Mucus & $75 \cdot 3$ & $48 \cdot 1$ & $21 \cdot 3$ & $11 \cdot 5$ & $13 \cdot 4$ & $34 \cdot 6$ & 0 & $5 \cdot 8$ & 0 & 0 & $16 \cdot 7$ & $\mathrm{p}<0.001$ \\
\hline Bad breath & $71 \cdot 1$ & $38 \cdot 5$ & $14 \cdot 4$ & $9 \cdot 6$ & $14 \cdot 4$ & 25 & 0 & $23 \cdot 1$ & 0 & $3 \cdot 8$ & 34.9 & $\mathrm{p}<0.0001$ \\
\hline Nausea & 95.8 & $67 \cdot 3$ & $3 \cdot 1$ & $15 \cdot 4$ & 1 & $9 \cdot 6$ & 0 & $3 \cdot 8$ & 0 & $3 \cdot 8$ & $23 \cdot 5$ & $\mathrm{p}<0.001$ \\
\hline Vomiting & 100 & $84 \cdot 6$ & 0 & 3.8 & 0 & $9 \cdot 6$ & 0 & 1.9 & 0 & 0 & $15 \cdot 7$ & $\mathrm{p}<0.01$ \\
\hline Dyspepsia & 93.8 & $82 \cdot 7$ & $6 \cdot 1$ & $11 \cdot 5$ & 0 & $5 \cdot 8$ & 0 & 0 & 0 & 0 & $7 \cdot 3$ & $\mathrm{p}<0.05$ \\
\hline Heartburn & $91 \cdot 8$ & $78 \cdot 4$ & $8 \cdot 2$ & $9 \cdot 8$ & 0 & $9 \cdot 8$ & 0 & 2 & 0 & 0 & $12 \cdot 2$ & $\mathrm{p}<0.01$ \\
\hline
\end{tabular}

TABLE II Severity of non-colonic symptoms in first time (1st) attenders, v chronic attenders (Chr)

\begin{tabular}{|c|c|c|c|c|c|c|c|c|c|c|c|c|}
\hline & \multicolumn{12}{|c|}{ Severity of symptoms $(\%)$} \\
\hline & \multicolumn{2}{|l|}{ Nil } & \multicolumn{2}{|l|}{ Mild } & \multicolumn{2}{|c|}{ Moderate } & \multicolumn{2}{|c|}{ Severe } & \multicolumn{2}{|c|}{ Very severe } & \multicolumn{2}{|l|}{$d f=4$} \\
\hline & lst & $C h r$ & $1 s t$ & Chr & lst & Chr & lst & Chr & lst & $C h r$ & $\chi^{2}$ & $\mathrm{p}$ \\
\hline $\begin{array}{l}\text { Backache } \\
\text { Urinary frequency } \\
\text { Leg pains } \\
\text { Headaches } \\
\text { Dysmenorrhea } \\
\text { Premenstrual tension } \\
\text { Lethargy }\end{array}$ & $\begin{array}{l}54 \cdot 6 \\
70 \cdot 5 \\
90 \cdot 7 \\
59 \cdot 8 \\
66 \cdot 7 \\
45 \cdot 5 \\
38 \cdot 1\end{array}$ & $\begin{array}{r}21 \cdot 2 \\
36 \cdot 5 \\
65 \cdot 4 \\
41 \cdot 2 \\
40 \cdot 0 \\
28 \cdot 9 \\
7 \cdot 7\end{array}$ & $\begin{array}{r}14 \cdot 4 \\
10 \cdot 5 \\
2 \cdot 1 \\
9 \cdot 3 \\
9 \cdot 1 \\
13 \cdot 6 \\
13 \cdot 4\end{array}$ & $\begin{array}{r}19 \cdot 2 \\
11 \cdot 5 \\
15 \cdot 4 \\
11 \cdot 8 \\
13.3 \\
8.9 \\
5.8\end{array}$ & $\begin{array}{r}26 \cdot 8 \\
27 \cdot 9 \\
7 \cdot 2 \\
29 \cdot 9 \\
19 \cdot 7 \\
30 \cdot 3 \\
42 \cdot 3\end{array}$ & $\begin{array}{l}25 \\
28 \cdot 8 \\
5 \cdot 8 \\
23 \cdot 5 \\
37 \cdot 8 \\
31 \cdot 1 \\
30 \cdot 8\end{array}$ & $\begin{array}{c}4 \cdot 1 \\
1 \cdot 1 \\
0 \\
1 \\
4 \cdot 5 \\
10 \cdot 6 \\
6 \cdot 2\end{array}$ & $\begin{array}{r}26 \cdot 9 \\
21 \cdot 2 \\
11 \cdot 5 \\
17 \cdot 6 \\
6 \cdot 7 \\
22 \cdot 2 \\
36 \cdot 5\end{array}$ & $\begin{array}{l}0 \\
0 \\
0 \\
0 \\
0 \\
0 \\
0\end{array}$ & $\begin{array}{r}7 \cdot 7 \\
1.9 \\
1.9 \\
5 \cdot 9 \\
2 \cdot 2 \\
8.9 \\
19 \cdot 2\end{array}$ & $\begin{array}{c}31 \cdot 4 \\
26 \cdot 9 \\
24 \cdot 8 \\
22 \cdot 2 \\
8 \cdot 7 \\
10 \cdot 64 \\
51 \cdot 7\end{array}$ & $\begin{array}{l}\mathrm{p}<0.0001 \\
\mathrm{p}<0.0001 \\
\mathrm{p}<0.001 \\
\mathrm{p}<0.001 \\
\mathrm{p}=0.07 \\
\mathrm{p}<0.05 \\
\mathrm{p}<0.0001\end{array}$ \\
\hline
\end{tabular}

an 'Index of definition'17 and a tentative ICD-9 psychiatric diagnosis.

Contingency table analysis ( $\mathrm{x} 2)$ was used to compare the distribution of scores between the two study groups.

\section{Results}

There was no difference between the two groups in terms of age or social class. Tables I and II show the difference between the severity of colonic and non-colonic symptoms for the two groups. With the exception of flatus, significantly greater proportions of chronic attenders reported their colonic symptoms as being of a severe nature in comparison with recent attenders (Table I). This was also true for non-colonic symptoms with the exception of dysmenorrhoea (Table II). Objective ratings by the gastroenterologist confirmed that chronic attenders had more severe symptoms: $76 \cdot 9 \%$ of the chronic attenders were rated as having moderate or severe symptoms in comparison with only $8 \cdot 2 \%$ of the first time attenders $(x 2=78 \cdot 9, \mathrm{df}=3$, $\mathrm{p}<0.0001$ ). There was no difference between the two groups in terms of the number of bowel actions reported per day $(p=0 \cdot 12)$ or the consistency of stool $(p=0 \cdot 16)$. Pellety stools were the most frequent types of stool reported $(34 \%$ of the first time attenders and $44 \%$ of the chronic attenders), with loose stools the second most frequent type $(22 \cdot 7 \%$ of first time attenders and $19.2 \%$ of chronic attenders). There was also no difference in the site of abdominal pain; the most common site for both groups being upper abdominal $(51 \cdot 7 \%$ first timers, $47 \cdot 1 \%$ chronic attenders). Chronic attenders were significantly more likely to experience constant, unremitting abdominal pain with 17 (32.7\%) describing such a symptom in comparison with only $14(14 \cdot 4 \%)$ of the first time attenders $(p<0.05)$. The pattern of the condition overall also differed significantly between the two groups, with $39 \cdot 2 \%$ of chronic attenders describing a pattern of continuous symptoms, without any periods of good health, in comparison with only $13.4 \%$ of the recent attenders (Table III). The degree to which patients felt abdominal symptoms interfered with various aspects of their lives is shown in Table IV. In every area, greater numbers of chronic attenders reported that irritable bowel syndrome symptoms had a moderate or severe limiting effect on their lives. These differences were highly significant.

There was no difference in the prevalence of psychiatric diagnosis between the two groups (49\% of the chronic attenders in comparison with $45 \cdot 4 \%$ of the first time attenders $(p=0 \cdot 67))$.

\section{Discussion}

This study clearly shows that patients with irritable bowel syndrome differ appreciably, depending upon whether they are attending the gastroenterological clinic for the first time or whether they are regular attenders with unresponsive symptoms. Although there is no difference in the site of abdominal pain or the frequency or consistency of stools, there are

TABLE III Overall pattern of illness in first (1st) time attenders $\mathrm{v}$ chronic attenders

\begin{tabular}{|c|c|c|}
\hline & $\begin{array}{l}\text { lst time } \\
\text { attenders } \\
\%\end{array}$ & $\begin{array}{l}\text { Chronic } \\
\text { attenders } \\
\%\end{array}$ \\
\hline $\begin{array}{l}\text { Severe symptoms constantly for years } \\
\text { Severe symptoms constantly for months }\end{array}$ & $\begin{array}{l}8 \cdot 2 \\
5 \cdot 2\end{array}$ & $\begin{array}{l}23 \cdot 5 \\
15 \cdot 7\end{array}$ \\
\hline $\begin{array}{l}\text { Symptoms present for several months } \\
\text { but with periods of good health in } \\
\text { between }\end{array}$ & 23 & $37 \cdot 3$ \\
\hline $\begin{array}{l}\text { Symptoms present for days-weeks with } \\
\text { good health in between }\end{array}$ & $51 \cdot 5$ & $15 \cdot 7$ \\
\hline Mild symptoms with acute exacerbations & $10 \cdot 3$ & 3.9 \\
\hline Symptoms change, no fixed pattern & 1 & 0 \\
\hline Any other & $\begin{array}{c}0 \\
\chi^{2}=29 \cdot 13\end{array}$ & $\begin{array}{c}3.9 \\
p<0.0001\end{array}$ \\
\hline
\end{tabular}


TABLE IV Limiting effect of irritable bowel syndrome symptoms on patient's lives in first time (1st) $\mathrm{v}$ chronic attenders (Chr)

\begin{tabular}{|c|c|c|c|c|c|c|c|c|c|c|c|c|}
\hline & \multicolumn{12}{|c|}{ Severity of limitation $(\%)$} \\
\hline & \multicolumn{2}{|l|}{ Nil } & \multicolumn{2}{|l|}{ Mild } & \multicolumn{2}{|c|}{ Moderate } & \multicolumn{2}{|c|}{ Severe } & \multicolumn{2}{|c|}{ Very severe } & \multicolumn{2}{|l|}{$d f=4$} \\
\hline & $1 s t$ & Chr & lst & Chr & lst & Chr & Ist & $C h r$ & $1 s t$ & Chr & $\chi^{2}$ & $\mathrm{p}$ \\
\hline $\begin{array}{l}\text { Work/housework } \\
\text { Social } \\
\text { Family } \\
\text { Mood state } \\
\text { Irritability } \\
\text { Housebound } \\
\text { Confined to bed }\end{array}$ & $\begin{array}{l}47 \cdot 4 \\
80 \cdot 4 \\
89 \cdot 7 \\
62 \cdot 9 \\
62 \cdot 9 \\
88 \cdot 7 \\
95 \cdot 9\end{array}$ & $\begin{array}{l}0 \\
19 \cdot 6 \\
45 \cdot 1 \\
19 \cdot 2 \\
23 \cdot 1 \\
42 \cdot 3 \\
63 \cdot 5\end{array}$ & $\begin{array}{r}21 \cdot 6 \\
12 \cdot 4 \\
7 \cdot 2 \\
16 \cdot 5 \\
15 \cdot 5 \\
7 \cdot 1 \\
2 \cdot 1\end{array}$ & $\begin{array}{l}25 \\
27 \cdot 5 \\
29 \cdot 4 \\
26 \cdot 9 \\
25 \\
17 \cdot 3 \\
11 \cdot 5\end{array}$ & $\begin{array}{r}28 \cdot 9 \\
6 \cdot 2 \\
3 \cdot 1 \\
18 \cdot 6 \\
19 \cdot 6 \\
4 \cdot 1 \\
1\end{array}$ & $\begin{array}{l}36 \cdot 5 \\
27 \cdot 5 \\
19 \cdot 6 \\
32 \cdot 7 \\
34 \cdot 6 \\
13 \cdot 5 \\
19 \cdot 2\end{array}$ & $\begin{array}{l}2 \cdot 1 \\
1 \\
0 \\
2 \cdot 1 \\
2 \cdot 1 \\
0 \\
1\end{array}$ & $\begin{array}{r}26 \cdot 9 \\
23 \cdot 5 \\
5 \cdot 9 \\
21 \cdot 2 \\
15 \cdot 4 \\
23 \cdot 1 \\
5 \cdot 8\end{array}$ & $\begin{array}{l}0 \\
0 \\
0 \\
0 \\
0 \\
0 \\
0\end{array}$ & $\begin{array}{l}11 \cdot 5 \\
2 \\
0 \\
0 \\
1 \cdot 9 \\
3 \cdot 8 \\
0\end{array}$ & $\begin{array}{l}56 \cdot 1 \\
57 \cdot 9 \\
36 \cdot 1 \\
32 \cdot 4 \\
26 \cdot 5 \\
43 \cdot 4 \\
27 \cdot 9\end{array}$ & $\begin{array}{l}\mathrm{p}<0.0001 \\
\mathrm{p}<0.0001 \\
\mathrm{p}<0.0001 \\
\mathrm{p}<0.0001 \\
\mathrm{p}<0.0001 \\
\mathrm{p}<0.0001 \\
\mathrm{p}<0.0001\end{array}$ \\
\hline
\end{tabular}

highly significant differences in terms of the severity of reported symptoms, the effect on patients' lives, and the longitudinal course of the condition. Chronic attenders are much more likely to experience constant, unremitting abdominal pain and report continuous symptoms with no breaks of good health than first time attenders at the clinic. The difference in symptom severity cannot be explained by the presence of psychiatric illness as the prevalence of psychiatric morbidity was similar in both groups.

There is increasing evidence that patients who complain of continuous, unremitting abdominal pain respond poorly to most treatments. ${ }^{18} 19$ Clearly, therefore, the proportion of chronic $v$ recent attenders in any treatment study will have a profound effect on outcome, as the chronic group are much more likely to contain patients who report continuous and severe symptoms in comparison with first time attenders. This emphasises the importance of carefully describing the nature of the irritable bowel syndrome population that is being studied in any evaluation of treatment. So great is the difference in severity and course of symptoms between first time attenders and chronic attenders, it is possible that there may also be differences in underlying gut motility and sensitivity. There are as yet, however, no studies on gut physiology that differentiate recent from chronic IBS attenders.

There is increasing evidence that community subjects with irritable bowel syndrome differ from those seeking health care.$^{20}$ In some respects the new referrals in this study represent a group halfway between these two extremes. What makes a new attender become a chronic patient is unclear but this may well be due to more subtle psychological and social mechanisms not detected by conventional assessment of psychiatric morbidity.

It is possible that within the group of first time attenders in this study, a small proportion would go on to become chronic attenders, unresponsive to treatment. This, however, would have tended to reduce the differences between the two groups rather than enhance them.

Future work on irritable bowel syndrome must not only attempt to categorise subjects according to symptoms and possibly physiological findings, but also take account of the course of the illness and the consulting pattern of patients.

1 Thompson WG, Heaton KW. Functional bowel disorders in apparently healthy people. Gastroenterology 1980; 79: 283-8.

2 Harvey RF, Sailih SY, Read AE. Organic and functional disorders in 2000 gastroenterology outpatients. Lancet 1983; disorders $632-4$.

3 Switz DM. What the gastroenterologist does all day. Gastroenterology 1976; 70: 1048-50

4 IBS Working Team Report. Handbook of International Congress of Gastroenterology, Rome, 1988.

5 Taylor I. Colonic motility and the irritable colon syndrome. In: Read NW, ed. Irritable bowel syndrome. London: Grune and Stratton, 1985: 89-103.

6 Creed FH, Guthrie EA. Psychological factors in the irritable bowel syndrome. Gut 1987; 28: 1307-18.

7 Holdsworth CD. Drug treatment of the irritable bowel syndrome. In: Read NW, ed. Irritable bowel syndrome. London: Grune and Stratton, 1985: 223-32.

8 Creed FH, Guthrie EA. Psychological treatment of the irritable bowel syndrome: a review. Gut 1989; 30: 1601-9.

9 Thompson WG. The irritable bowel. Gut 1984; 25: 305-20.

10 Esler MD, Goulston KJ. Levels of anxiety in colonic disorders N Englf Med 1973; 288: 16-20.

11 Harvey RF, Mauad EC, Brown AM. Prognosis in the irritable bowel syndrome; a 5 year prospective study. Lancet 1987; i: 963-5.

12 Klein KB. Controlled treatment trials in the irritable bowel syndrome: a critique. Gastroenterology 1988; 95: 232-41

13 Maxton DG, Morris JA, Whorwell PJ. Ranking of symptoms by patients with irritable bowel syndrome. BMF 1989; 299: 1138-9.

14 Whorwell PJ, McCallum M, Creed FH, Roberts CT. Noncolonic features of irritāble bowel syndrome. Gut 1986; 27: $37-40$.

15 Dean C, Surtees PG, Sashidharan SP. Comparison of research diagnostic systems in an Edinburgh Community: associations with demographic factors. BrF Psychiatry $1983 ; 142$ : $238-47$.

16 Wing JK, Cooper JE, Sartorius N. The measurement and classification of psychiatric symptoms. London: Cambridge University Press, 1974

17 Wing JK, Sturt E. The PSE-ID-CATEGO systems. Supplementary manual. London: MRC Social Psychiatry Unit, 1978.

18 Whorwell PJ, Prior A, Colgan SM. Hypnotherapy in severe irritable bowel syndrome: further experience. Gut $1987 ; 28$ : 423-5.

19 Guthrie EA, Creed FH, Dawson D, Tomenson B. A controlled trial of psychological treatment for the irritable bowe syndrome. Gastroenterology 1991; 100: 450-2.

20 Sandler RS, Drossman DA, Nathan HP, McKee DC Symptom complaints and health care seeking behaviour in subjects with bowel dysfunction. Gastroenterology 1984; 87 : $324-8$. 